\title{
JR5s, University of Chicago Press Journals, and the JSTOR Bump
}

Matt Jabaily, Electronic Resources and Serials Librarian, University of Colorado Colorado Springs

In 2016, University of Chicago Press Journals ended their participation in the JSTOR Current Scholarship program and elected instead to publish on the Atypon platform. With this change in platform came a dramatic decline in the apparent usage of the journals to which the library subscribed as part of the Complete Chicago Package. This poster presents some of the data the UCCS Kraemer Family Library used to better understand the decline in usage and to make subscription decisions going forward.

\section{How did the transition from JSTOR to Atypon affect downloads and cost per download?}

Prior to COUNTER release 4, libraries typically relied on the JR1 report to determine usage. When comparing the JR1 from JSTOR for 2015, the last year the UChicago Journals were on that platform, to the Atypon use for 2016, the difference is immense. There is an apparent dramatic decline in number of downloads and a significant rise in cost per download. Looking at the most cost effective titles in terms of cost per download $(\mathrm{CpD})$, a similar decline in value is clear.

\section{JR1 Full Text Downloads}

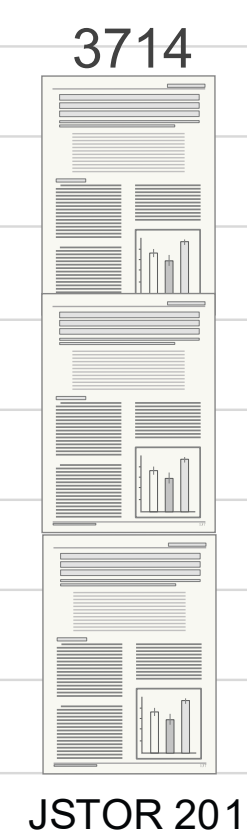

JR1 Calculated Cost per Download

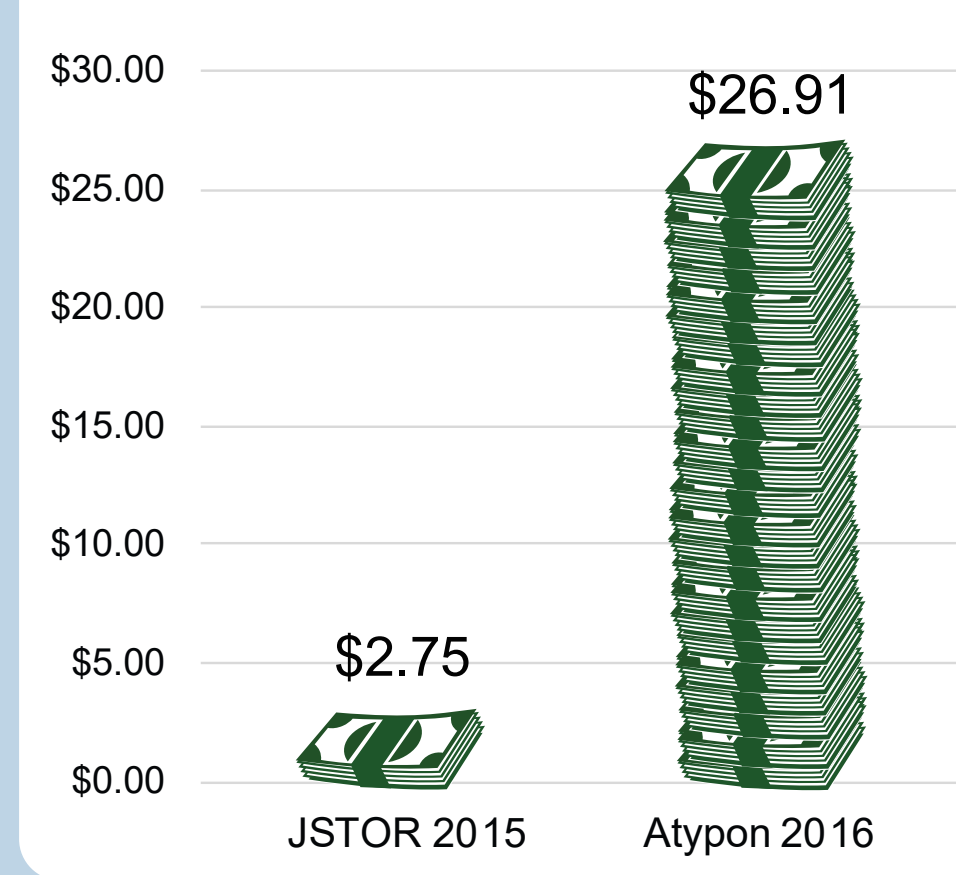

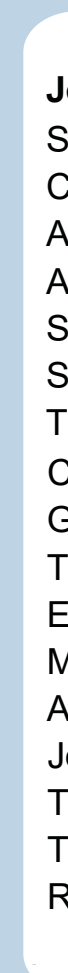

\begin{tabular}{|c|c|c|c|}
\hline $\begin{array}{c}\text { JSTOR } \\
\text { Downloads }\end{array}$ & $\begin{array}{r}\text { JSTOR } \\
\text { CpD }\end{array}$ & $\begin{array}{l}\text { Atypon } \\
\text { Downloads }\end{array}$ & $\begin{array}{c}\text { Atypon } \\
C p D\end{array}$ \\
\hline N/A & $\mathrm{N} / \mathrm{A}$ & 37 & $\$ 5.65$ \\
\hline 265 & $\$ 1.36$ & 60 & $\$ 6.02$ \\
\hline 111 & $\$ 1.72$ & 23 & $\$ 8.30$ \\
\hline 440 & $\$ 1.12$ & 44 & $\$ 11.20$ \\
\hline 352 & $\$ 1.09$ & 29 & $\$ 13.24$ \\
\hline 60 & $\$ 4.58$ & 17 & $\$ 16.18$ \\
\hline 162 & $\$ 1.40$ & 12 & $\$ 18.83$ \\
\hline 127 & $\$ 2.21$ & 12 & $\$ 23.42$ \\
\hline 77 & $\$ 2.21$ & 7 & $\$ 24.29$ \\
\hline 52 & $\$ 4.42$ & 9 & $\$ 25.56$ \\
\hline 48 & $\$ 5.63$ & 8 & $\$ 33.75$ \\
\hline 64 & $\$ 4.02$ & 7 & $\$ 36.71$ \\
\hline 59 & $\$ 3.97$ & 5 & $\$ 46.80$ \\
\hline 35 & $\$ 11.77$ & 7 & $\$ 58.86$ \\
\hline 92 & $\$ 4.77$ & 7 & $\$ 62.71$ \\
\hline $\begin{array}{l}92 \\
49\end{array}$ & $\$ 8.08$ & 6 & $\$ 66.00$ \\
\hline 1269 & & & \\
\hline
\end{tabular}

How does the comparison change if we look only at paid subscription content?

Using the COUNTER JR5, which shows full text downloads by year of publication, we can make a much more fair comparison. When comparing downloads only from the current year and the past three years (roughly equivalent to the embargo period before content becomes available through a package) the gap is much smaller. Nonetheless, there is still a large disparity between the platforms.

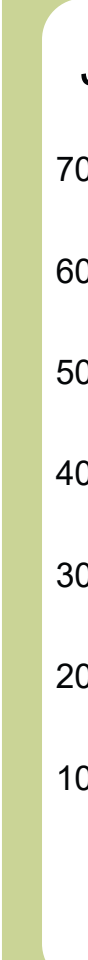

JR5 Full Text Downloads Past 4 Years

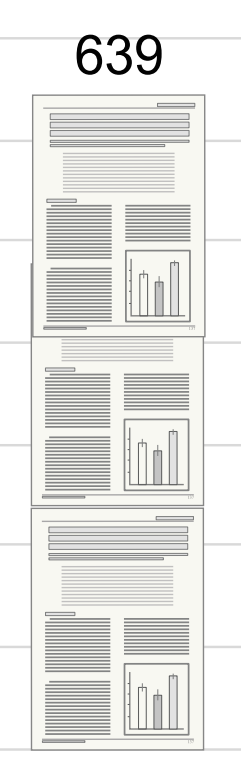

JSTOR 2015

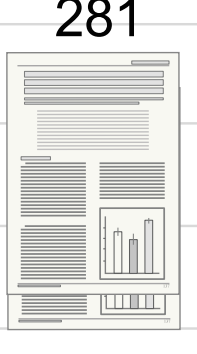

Atypon 2016
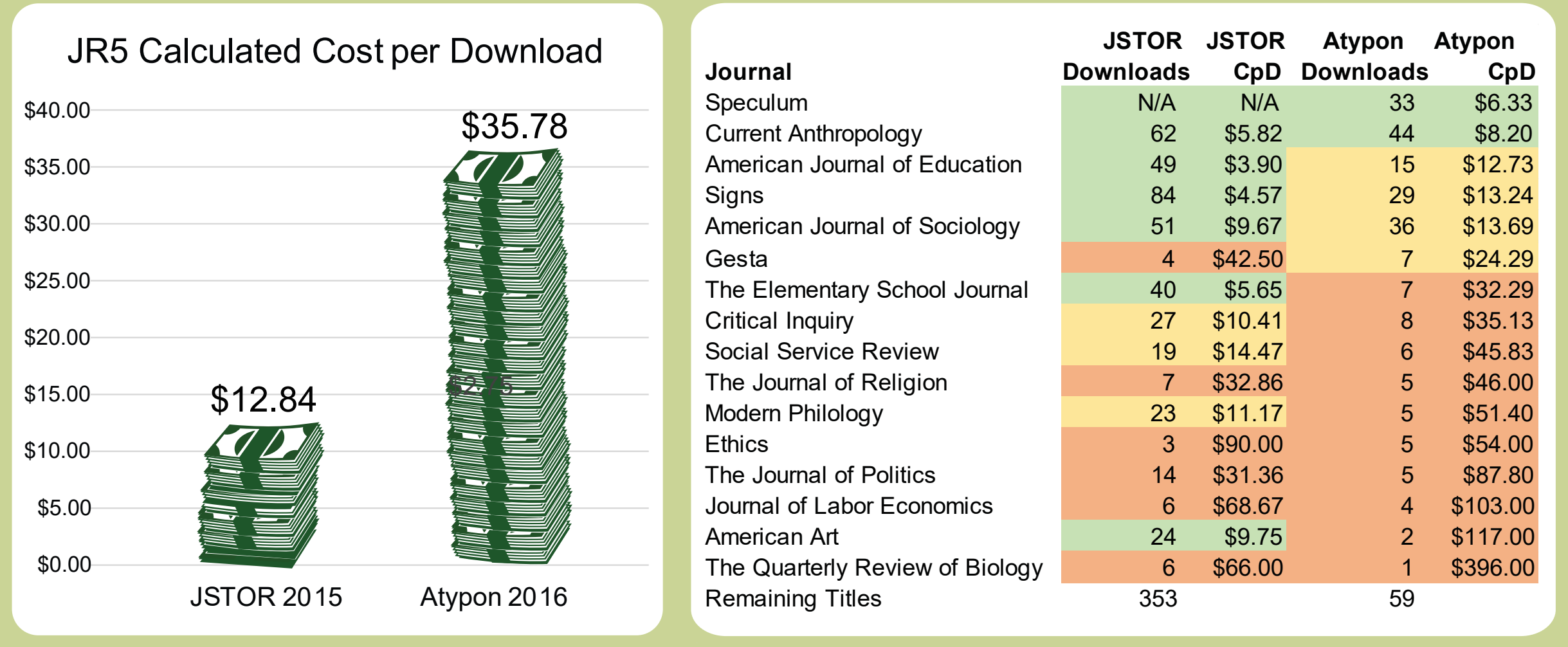

What is a full text UChicago Journals sells most articles to individuals for $\$ 10$ each. Although fulfillment services, like Reprints Desk download worth? add a service fee, the price is still less than our $\mathrm{CpD}$ for most titles. Subscriptions add some value in their convenience, but an unmediated PPV program would likely be the most desirable option for libraries like ours.

\section{Is JSTOR counting more aggressively?}

A possible explanation for higher usage statistics is more aggressive counting. For example, if the architecture encourages a single user to trigger both an HTML and PDF download. This was not evident in the data.
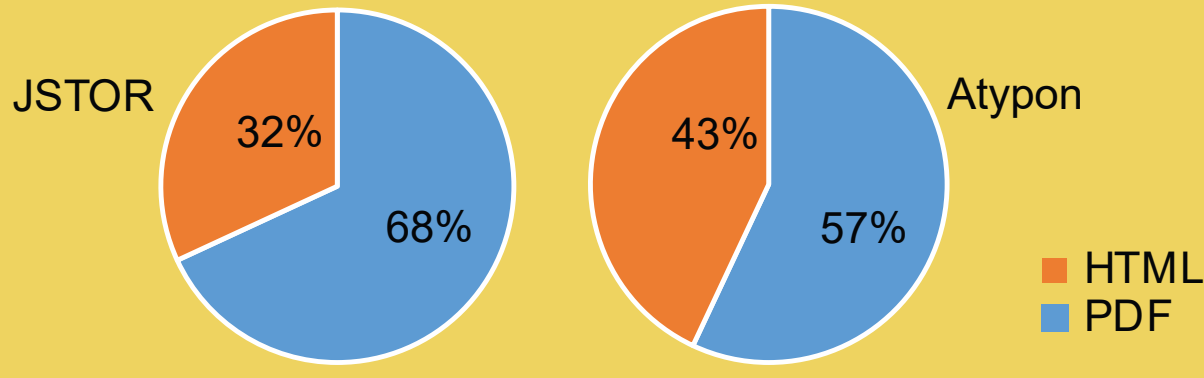

What about titles transferred to other publishers?

Title publisher changes can have outsized effects on package value. UChicago took over Speculum in 2016. It had 37 uses that year, which was almost $10 \%$ of the package's use, increasing the value of the package. If a popular title leaves a publisher, however, it could take a large percentage of the package's use with it.

Do direct searchers of JSTOR give it a platform advantage that increases use?

JSTOR data shows a

large portion of our use was from direct JSTOR searches or Google/

Google Scholar. Their data also showed 95 turnaways for UChicago

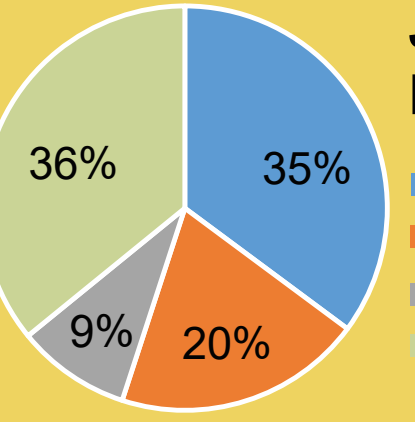
JSTOR Visit Referring Sources titles in 2016

What Changes Did We Make Based on the Data?

After a careful review of the data, we elected to cancel our Complete Chicago Package. Instead, we subscribed to individual titles. We factored in statistics from the first half of 2017 and kept subscriptions to all titles with a Cpd of less than $\$ 30$. We also maintained one other title by faculty request.

$13 / 72(18 \%)$

255/359 (71\%)

Titles Maintained 2016 Uses Accounted For $\$ 3,874 / \$ 11,500$ (34\%) Amount Paid 